\title{
An application of three different field methods to monitor changes in Urumqi Glacier No. 1, Chinese Tien Shan, during 2012-18
}

\section{Article \\ Cite this article: Li H, Wang P, Li Z, Jin S, Xu C, Liu S, Zhang Z, Xu L (2022). An application of three different field methods to monitor changes in Urumqi Glacier No. 1, Chinese Tien Shan, during 2012-18. Journal of Glaciology 68(267), 41-53. https://doi.org/10.1017/ jog.2021.71}

Received: 31 August 2020

Revised: 30 May 2021

Accepted: 1 June 2021

First published online: 24 June 2021

\section{Key words:}

Chinese Tien Shan; glacier change; RTK-GNSS; TLS; UAV; Urumqi Glacier No. 1

\section{Author for correspondence:}

Puyu Wang,

Email: wangpuyu@lzb.ac.cn (c) The Author(s), 2021. Published by Cambridge University Press. This is an Open Access article, distributed under the terms of the Creative Commons Attribution licence (http://creativecommons.org/licenses/by/4.0/), which permits unrestricted re-use, distribution, and reproduction in any medium, provided the original work is properly cited.
Hongliang $\mathrm{Li}^{1,2}$, Puyu Wang ${ }^{1,2,3}$, Zhongqin $\mathrm{Li}^{1,3,4}$, Shuang $\mathrm{Jin}^{1}$, Chunhai $\mathrm{Xu}^{1}$, Shuangshuang Liu ${ }^{1,2}$, Zhengyong Zhang ${ }^{3}$ and Liping $X^{3}$

\begin{abstract}
${ }^{1}$ State Key Laboratory of Cryosphere Science, Northwest Institute of Eco-Environment and Resources, Chinese Academy of Sciences, Lanzhou 730000, China; ${ }^{2}$ University of Chinese Academy of Sciences, Beijing 100049, China; ${ }^{3}$ College of Science, Shihezi University, Shihezi, Xinjiang 832003, China and ${ }^{4}$ College of Geography and Environmental Science, Northwest Normal University, Lanzhou 730070, China
\end{abstract}

\begin{abstract}
This study deploys RTK-GNSS in 2012, TLS in 2015 and UAV in 2018 to monitor the changes of Urumqi Glacier No. 1 (UG1), eastern Tien Shan, and analyzes the feasibility of three technologies in monitoring the mountain glaciers. DEM differencing shows that UG1 has experienced a pronounced thinning and mass loss for the period of 2012-18. The glacier surface elevation change of $-0.83 \pm 0.57 \mathrm{~m}$ w.e. $\mathrm{a}^{-1}$ has been recorded for $2012-15$, whereas the changes of glacier tongue surface elevation in 2015-18 and 2012-18 were $-2.03 \pm 0.95$ and $-1.34 \pm 0.88 \mathrm{~m}$ w.e. $\mathrm{a}^{-1}$, respectively. The glacier area shrunk by $0.07 \pm 0.07 \times 10^{-3} \mathrm{~km}^{2}$ and the terminus retreat rate was $6.28 \pm$ $0.83 \mathrm{~m} \mathrm{a}^{-1}$ during 2012-18. The good agreement between the glaciological and geodetic specific mass-balances is promising, showing the combination of the three technologies is suitable to monitor glacier mass change. We recommend application of the three technologies to assess each other in different locations of the glacier, e.g. RTK-GNSS base stations, ground control points, glacier tongue and terminus, in order to avoid the inherent limitations of each technology and to provide reliable data for the future studies of mountain glacier changes in western China.
\end{abstract}

\section{Introduction}

Glaciers are not only recognized as one of the best indicators of climate variabilities, but also feed many rivers in High-Mountain Asia (Immerzeel and others, 2010). Under a recent warming climate, mountain glaciers are losing mass. They are thinning and shrinking, and their tongues are receding. Such glacier loss has a direct impact on water resources and ecological environment (Wang and others, 2015). Receding glaciers are also associated with increased risks from ice avalanches (Shen and others, 2013), glacial lake outburst floods (Simon and others, 2019), icefalls (Shen and others, 2013) and glacial debris flows (Hock and others, 2019). The annual shrinkage rate of area and ice volume in the Tien Shan were 0.7 and $0.83 \% \mathrm{a}^{-1}$, respectively, and the mass loss increased by $27 \%$ with the increasing temperature over the past five decades (Farinotti and others, 2015). By comparison between the first and second Chinese Glacier Inventory datasets, from the 1960s to 2000s, glacier area shrunk 19\% on average in the Chinese Tien Shan (Wang and others, 2020). The mass loss of monitored glaciers in the Tien Shan has accelerated since the late 1990s, with a slight slowing down after 2010 (Wang and others, 2020). Remote-sensing-based geodetic mass-balance estimates revealed a mean rate of surface elevation change was $-0.58 \pm 0.21 \mathrm{~m} \mathrm{a}^{-1}$ during $2003-09$ in the Tien Shan (Gardner and others, 2013). The corresponding changes in western and eastern Tien Shan regions were $-0.40 \pm 0.05$ and $-0.75 \pm 0.05 \mathrm{~m} \mathrm{a}^{-1}$, respectively (Wang and others, 2015). Glaciers in the Tien Shan have experienced continuous mass loss and area shrinkage during the past few decades. These changes can increase runoff in the short term, but may reduce the total runoff on long-term scales (Huss and Hock, 2018). For example, glacier changes in the Tien Shan have been contributing to a reduced runoff since the mid-1990s (Deng and others, 2018), which reflects the regulate mechanism of glaciers on water resources in the basin.

Studies of glacier mass balance as well as glacier area and terminus (length) change are used to assess climate variabilities (Andreassen and others, 2005; Zemp and others, 2013), and allow us to improve models for glacier ablation and glacier hydrology. Although many studies have focused on spatio-temporal changes of glaciers in the Tien Shan and their contribution to sealevel change (Yao and others, 2012; Shangguan and others, 2015; Sun and others, 2015; Brun and others, 2017; Liu and others, 2017; Wang and others, 2019; Yang and others, 2019), since long-term monitoring of glaciers remains scarce, limiting studies used to verify the accuracy of these results, except for Urumqi Glacier No. 1 (UG1). UG1 located in the eastern Tien Shan is one of the reference glaciers in the World Glacier Monitoring Service network and provides one of the longest time series and most detailed mass-balance measurement in China (Li and others, 2011; Zemp and others, 2013). Several studies have focused on the mass balance, area and terminus measurements on UG1 (Li and others, 2003, 2011; Jing and others, 2006; Wang and others, 2014, 2016; Xu and others, 2018, 2019). However, the accuracy of glacier change results has been greatly improved with the application of various field observation 


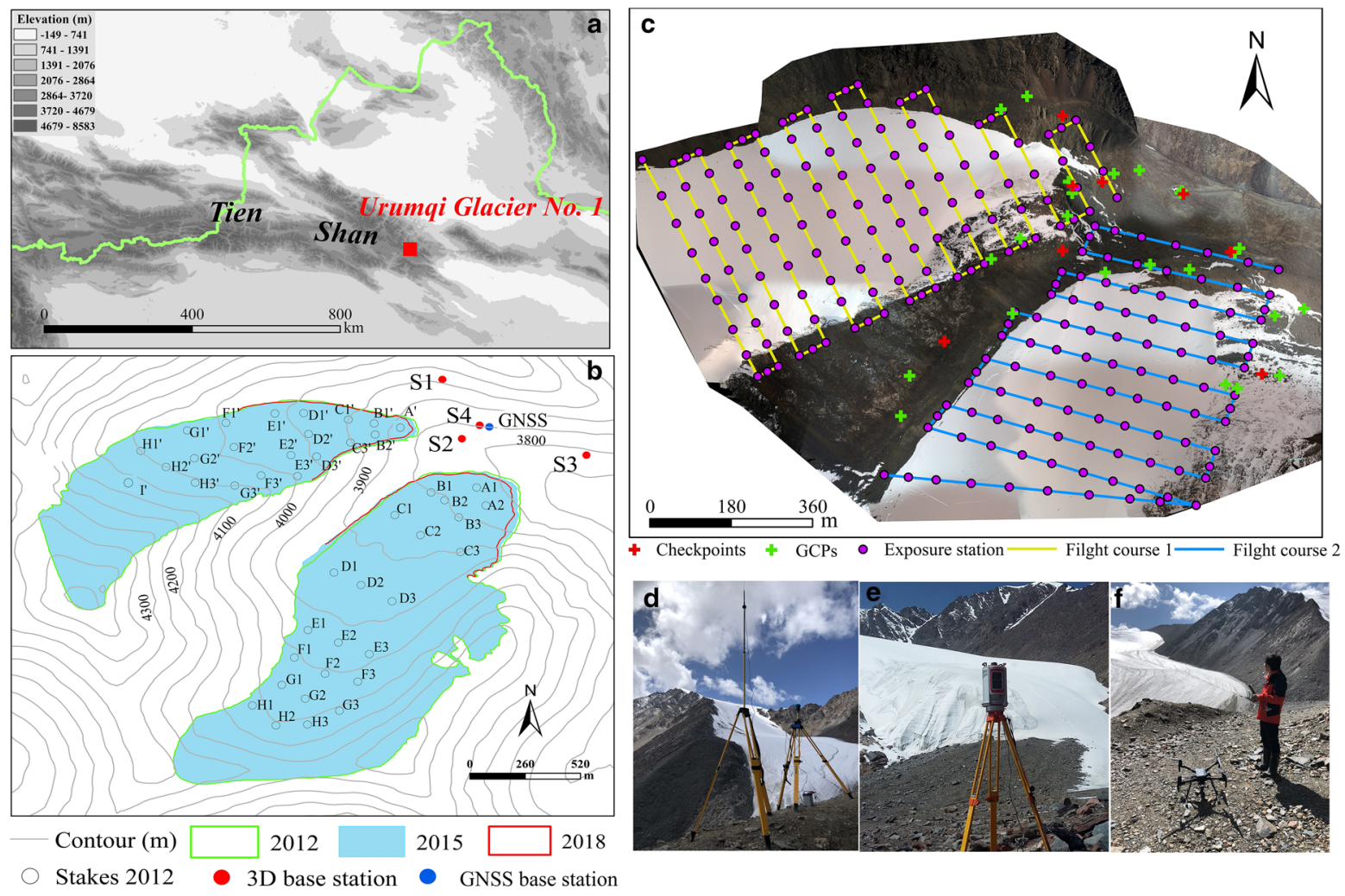

Fig. 1. Overview of the study area. (a) Location map of UG1 in the eastern Tien Shan. (b) The topographic map of UG1 with glacier boundary in different periods. The spatial distributions of TLS positions and RTK-GNSS base station are shown in red and blue circles. (c) Flight coverage area on 24 April 2018 . Photographs of RTK-GNSS survey base station, TLS survey and UAV survey are shown in (d), (e) and (f), respectively.

methods in recent years. For example, the Real Time Kinematic-Global Navigation Satellite System (RTK-GNSS) is currently the most accurate positioning method in GNSS measurement. RTK-GNSS can achieve dense points coverage and is suitable for glacier surface elevation measurement (Ding and others, 2019). The terrestrial laser scanner (TLS) has accurately monitored summer and annual surface elevation and geodetic mass balance as well as delineated accurate glacier boundary (Xu and others, 2017). TLS systems have been successfully monitoring the surface changes of a temperate Alpine glacier in Switzerland as well as the mass balance of five small glaciers in the European Alps at hourly and seasonal scales (Gabbud and others, 2015; Fischer and others, 2016). Therefore, TLS has not only the potential to monitor remote and inaccessible glacier area where no glaciological measurements are available (Xu and others, 2019), but also has become a tool for monitoring seasonal changes of individual glaciers due to its wavelengths in the near-infrared, allowing long-range scanning of glacier surfaces (Gabbud and others, 2015). Unmanned aerial vehicle (UAV) photogrammetry is widely applied in monitoring glacier changes during recent years. UAVs have been used on polar glaciers (Whitehead and others, 2014a, 2014b; Bhardwaj and others, 2016) as well as mountain glaciers in the Himalaya (Immerzeel and others, 2014) and the Andes (Wigmore and Mark, 2017). Relatively inexpensive UAVs with advantages of small size, flexibility and centimeter-level resolution, can extract glacier surface elevation and ice velocity (Kraaijenbrink and others, 2016; Che and others, 2019).

In this study, RTK-GNSS, TLS and UAV surveys conducted in 2012, 2015 and 2018 were used to obtain the DEMs of the glacier surface, respectively. The three high-resolution DEMs available allowed us to study the glaciological and geodetic methods to determine the mass balance. Therefore, the main objectives of this study include two aspects: (1) to quantify the mass loss of
UG1 during the period 2012-18, and (2) to assess the feasibility of applying the three technologies.

\section{Study area}

Chinese Tien Shan lies in the arid region of central Asia, extending $2400 \mathrm{~km}$ from east to west and accounting for more than 34.5\% of the total area of the Xinjiang Uygur Autonomous Region ( $\mathrm{Hu}$ and others, 2004). The topography is dominated by high mountains ranging from $\sim 4000$ to $6000 \mathrm{~m}$ a.s.l. (Fig. 1a). The Tien Shan was influenced by the Siberian anticyclonic circulation, the westerly jet stream in the upper troposphere, and the cyclonic disturbances of the west wind circulation (Farinotti and others, 2015). There are 7934 glaciers in the Chinese Tien Shan with a total area of 7179.77 $\mathrm{km}^{2}$ and ice volume of $756.48 \mathrm{~km}^{3}$ according to Second Glacier Inventory of China (Liu and others, 2015).

UG1 $\left(43^{\circ} 06^{\prime} \mathrm{N}, 86^{\circ} 49^{\prime} \mathrm{E}\right)$, a northeast-orientated valley glacier at the headwaters of Urumqi River situated on the Tianger Summit II in the eastern Tien Shan, has the longest continuous datasets among the glaciers in China (Fig. 1b). It has two branches. The east branch (EB) and west branch (WB) of the glacier separated completely in 1993 (Li and others, 2011). It ranges from 4450 to $3743 \mathrm{~m}$ a.s.l. at the terminus. UG1 thinned at the rate of $0.34 \mathrm{~m} \mathrm{a}^{-1}$ during $1980-2012$, and the mean ice thickness was $44.5 \mathrm{~m}$ in 2012. The average annual mass balance was $-0.46 \mathrm{~m}$ w.e. $\mathrm{a}^{-1}$ during the period 1980-2012, the average terminus retreat rate was $4.4 \mathrm{~m} \mathrm{a}^{-1}$ in the same period with significant differences between the EB and WB caused by topographic differences (Wang and others, 2016).

\section{Data and methods}

\subsection{Glacier surface elevation, area and terminus}

Glacier surface elevation and terminus location of UG1 were obtained using RTK-GNSS (Unistrong E650) on 1 September 
Table 1. Data information for UG1 used in this study

\begin{tabular}{llll}
\hline Observation time & Observation item & $\begin{array}{l}\text { Instrument/ } \\
\text { method }\end{array}$ & Spatial or temporal resolution \\
\hline 1 September 2012 & RTK-GNSS_DEM & RTK-GNSS & $5 \mathrm{~m}$ \\
25 April 2015 & TLS_DEM & TLS & $1 \mathrm{~m}$ \\
24 April 2018 & UAV_DEM & UAV & $0.36 \mathrm{~m}$ \\
$1980-2018$ & Terminus change & RTK-GNSS & From the end of April to early September every year \\
1 September 2012-25 April 2015; & Glaciological specific mass & $\begin{array}{l}\text { Stakes/snow } \\
\text { pits }\end{array}$ & From the end of April to early September every year; 44 and 26 ablation \\
25 April 2015-24 April 2018 & balance & & stakes observed in 2012-15 and 2015-18, respectively \\
\hline
\end{tabular}

2012. The GNSS base station was placed at the S2 near the glacier terminus (Fig. 1b). The other receiver was used in kinematic mode as a rover to survey the area on and around the glacier with a sampling interval of $20 \mathrm{~m}$. The accuracy of the GNSS survey points has been reported to be within $\pm 1 \mathrm{~cm}$ horizontally and $\pm 2 \mathrm{~cm}$ vertically. The intercoordinate system conversion was performed using Unistrong Landtop (Wang and others, 2016). All GNSS point data were re-projected to the Universal Transverse Mercator (UTM 45N) coordinate system, and referenced to the World Geodetic System 1984 (WGS84, EPSG: 4326). The point data were interpolated by the Kriging interpolation method to produce the RTK-GNSS_DEM, with a grid resolution of $5 \mathrm{~m}$ (Table 1).

Glacier surface elevation was measured again by Riegl VZ -6000 TLS on 25 April 2015. TLS surveys of UG1 were performed from four scan positions (S1, S2, S3 and S4) (Fig. 1b). To avoid ground motion and to obtain accurate coordinates of point clouds, each scan position was fixed using reinforced concrete. The four scan positions were surveyed using the RTK-GNSS to obtain accurate direct georeferencing and registration. In order to obtain the maximum scanning range of the glacier surface, coarse scanning was first implemented with vertical and horizontal angles range of $60-120^{\circ}$ from zenith and $0-360^{\circ}$, respectively, and the laser pulse repetition rate was set to $50 \mathrm{kHz}$. A fine scan is a rectangular field-of-view scan, and the selected field should always cover the entire glacier to guarantee the overlap percentage of four scans was at least $30 \%$. The overlap percentage of each pair of scans was not $<30 \%$ to meet the requirements of multi-station adjustment, which was used for the data registration of each scan position according to the iterative closest point algorithm (Besl and McKay, 1992). RiSCAN $\mathrm{PRO}^{\oplus} \mathrm{v} 1.81$ software was applied to process original point cloud data of UG1, including direct georeferencing, point cloud registration, point cloud data compression (Perroy and others, 2010) and a terrain filtering (RIEGL Laser Measurement Systems, 2014). Finally, the TLS_DEM was generated with a spatial resolution of $1 \mathrm{~m}$ from TLS measurement (Table 1).

The glacier surface of UG1 was surveyed on 24 April 2018 by using a UAV (MATRICE 200) made by DJI Technology Co., Ltd. Two flights were carried out with a flying height of 120 $\mathrm{m}$ for each flight. The overlap between the two flights was $80 \%$, and the camera pitch angle was $70^{\circ}$. The flight parameters were set in Pix4D Mapper software. However, because of the lack of battery power caused by the low temperature in the highaltitude mountainous area, the UAV survey could be only conducted over the glacier tongue as shown in Figure 1c. The total coverage area of UAV survey was $1.39 \mathrm{~km}^{2}$. The takeoff point and survey range of UAV is also shown in Figure 1. Twenty-one ground control points (GCPs) marked by $1.5 \mathrm{~m} \times$ $1.5 \mathrm{~m}$ red waterproof cloths with a yellow cross in the center evenly distributed on the off-glacier regions, were surveyed by RTK-GNSS simultaneously. The coordinates of GCPs are adopted in the WGS84 datum (EPSG: 4326 ) and UTM $45 \mathrm{~N}$ projection. The photographs and GCPs were imported into Pix4D
Mapper for automatic processing, and finally UAV_DEM was generated (Table 1).

In order to compare DEMs from different periods, this paper resampled DEMs to a spatial resolution of $5 \mathrm{~m}$, and carried out coordinate normalization using WGS84 datum (EPSG: 4326) and UTM $45 \mathrm{~N}$ projection.

\subsection{Accurate glacier outline extraction}

An accurate and updated glacier area was important for both geodetic and glaciological mass-balance calculations (Zemp and others, 2013). Fresh snow cover probably led to an overestimate of glacier extent at the beginning of the ablation season. To reduce the influence of snow cover and extract accurate glacier outlines, we mainly considered glacier extents at the end of the ablation season. Glacier boundary was derived from a high-resolution image data in August 2012 as shown in Figure 1b (Yao and others, 2015). Glacier boundary in 2015 was extracted from shaded relief based on TLS_DEM. The UAV_DEM has only covered the glacier tongue (Fig. 1c). Due to the incomplete boundary in 2018 extracted from shaded relief, missing upper boundary in 2018 was filled with the upper boundary in 2015 considering the upper glacier boundary generally remains in steady state (Xu and others, 2019). The manually delineating glacier boundaries are shown in the shaded relief (Fig. 2).

\subsection{Mass-balance measurement}

The mass-balance year of UG1 is defined from 1 September in the previous year to 31 August (Li and other, 2020). The single-point specific mass balance has been measured by stake/snow pit method from the end of April to early September each year. Forty-four ablation stakes were drilled into the glacier surface in 2012 using a steam drill and arranged in seven or eight rows at different altitudes of the two branches (Fig. 1b). The measurements include the stake vertical height above the glacier surface, superimposed ice thickness and the density and thickness of each snow/firn layer at individual ablation stakes. Snow and ice density presumably use field measurement values when the vertical height of snow/firn layer $>5 \mathrm{~cm}$. Glaciological specific mass balance can be calculated as follows (Wang and others, 2017):

$$
b_{n}=b_{\mathrm{s}}+b_{\mathrm{ice}}+b_{\mathrm{si}}
$$

where $b_{s}, b_{\text {ice }}$ and $b_{\text {si }}$ are mass balance of snow, glacier ice and superimposed ice, respectively. Measured stake and snow pit heights combined with snow, firn and ice density were converted into mass (w.e.) to calculate glacier-wide mass balance. The detailed information of mass-balance datasets used in this study is shown in Table 1.

\subsection{Accuracy analysis}

\subsubsection{Glacier surface elevation change co-registration}

The RTK-GNSS_DEM and UAV_DEM were adjusted based on the TLS_DEM. The uncertainty of the DEMs $\left(\sigma_{\mathrm{DEM}}\right)$ is estimated by comparing the DEM values with an independent set of GCPs 


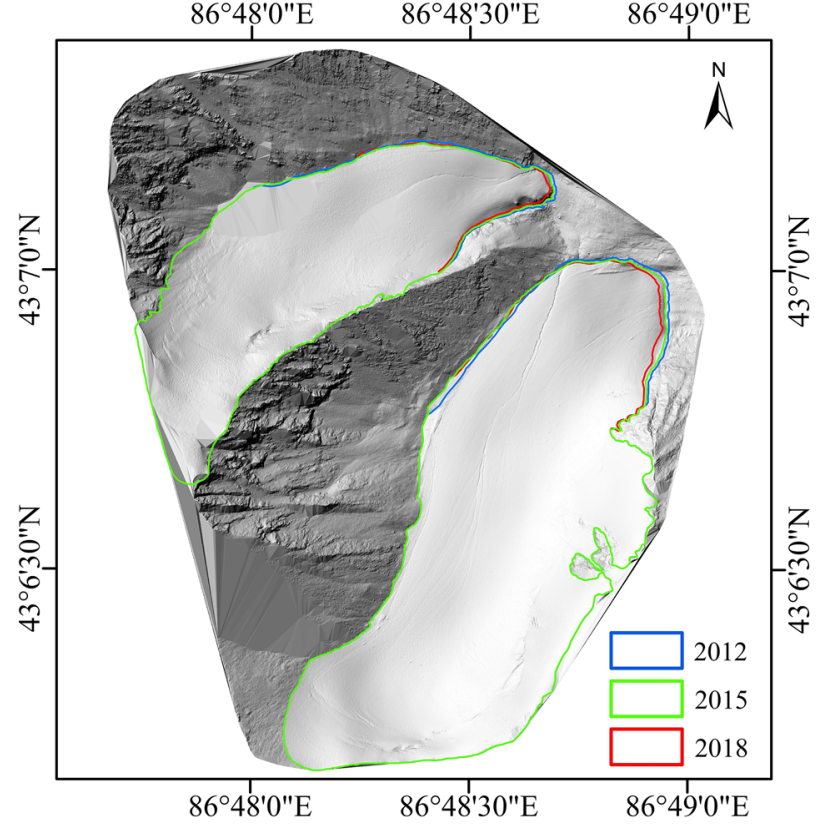

Fig. 2. Shaded relief of UG1 calculated based on the TLS_DEM (on 25 April 2015) with the glacier boundary in 2012 (blue), 2015 (green) and 2018 (red). The shaded relief calculated through Arcmap 10.3 software with the solar azimuth angle and elevation angle set to $315^{\circ}$ and $60^{\circ}$, respectively.

on off-glacier regions. Ten independent GCPs on off-glacier regions were selected to perform the uncertainty of the DEMs using the following equation (Paul and others, 2015):

$$
\sigma_{\mathrm{DEM}}=\frac{\sum_{1}^{n}\left(Z_{\mathrm{DEM} 1}-Z_{\mathrm{DEM} 2}\right)}{n}
$$

where $n$ is the number of off-glacier regions DEM grid cells. The results are shown in Table 2.

In order to make the differencing of the DEMs in different periods, a co-registration of the DEMs was necessary before extracting glacier surface elevation changes (Nuth and others, 2011). Based on the cosinusoidal relationship between elevation difference and topographical parameters (slope and aspect), the horizontal displacements and vertical biases were rectified simultaneously (Figs 3a, c, e). The biases, caused by different spatial resolutions between the two datasets, were refined using the relationship between elevation differences and maximum curvatures for both on- and off-glacier regions (Gardelle and others, 2012) as shown in Figures 3b, $\mathrm{d}$ and $\mathrm{f}$. The overall errors of the derived surface elevation changes $(E)$ can then be estimated using $E_{\mathrm{m}}$ and $E_{\sigma}$ from off-glacier regions as following and the estimated results is as shown in Table 2. After co-registration, mean elevation differences $\left(E_{\mathrm{m}}\right)$ in off-glacier regions ranged from -0.23 to $0.94 \mathrm{~m}$. This indicated elevation differences in the off-glacier regions had stabilized after these adjustments, making the processed DEMs suitable for estimating glacier surface elevation and mass balance:

$$
\begin{gathered}
\mathrm{SE}=\frac{E_{\sigma}}{\sqrt{N}} \\
E=\sqrt{E_{\mathrm{m}}+\mathrm{SE}}
\end{gathered}
$$

\subsubsection{Glacier area and terminus}

The uncertainty in the glacier area and terminus changes for an individual glacier during $2012-18$ can be estimated according to
Williams and others (1997), Hall and others (2003) and Silverio and Jaquet (2005):

$$
\begin{gathered}
U_{\mathrm{T}}=\sqrt{\sum \lambda^{2}}+\sqrt{\sum \varepsilon^{2}} \\
U_{\mathrm{A}}=\sum \lambda^{2} \times \frac{2 \times U_{\mathrm{T}}}{\sqrt{\sum \lambda^{2}}}+\sum \varepsilon^{2}
\end{gathered}
$$

where $U_{\mathrm{T}}$ and $U_{\mathrm{A}}$ are the uncertainty of the glacier terminus and area, respectively. $\lambda$ is the resolution of each individual image, and $\varepsilon$ is the registration error of each image. Especially, the registration error keeps within one pixel. The overall evaluation indicated that the uncertainties of glacier terminus and area change are $5 \mathrm{~m}$ and $0.07 \times 10^{-3} \mathrm{~km}^{2}$ in $2012-15,1 \mathrm{~m}$ and $0.01 \times 10^{-3} \mathrm{~km}^{2}$ in $2015-18$ and $5 \mathrm{~m}$ and $0.07 \times 10^{-3} \mathrm{~km}^{2}$ in $2012-18$, respectively.

\subsubsection{Glacier mass balance}

The geodetic mass balance is calculated by multiplying the volume change with the mean density, and then dividing by the area which refers to the larger glacier area of the two periods (Zemp and others, 2013). The uncertainty of glacier-wide elevation changes $\left(\sigma_{\Delta h}^{2}\right)$ for individual glacier was quantified using the geostatistical analysis methods of Rolstad and others (2009). In order to convert volume change to w.e. for the entire glacier, a density of $850 \mathrm{~kg} \mathrm{~m}^{-3}$ $(\rho)$, with its uncertainty of $\pm 60 \mathrm{~kg} \mathrm{~m}^{-3}\left(\sigma_{\rho}\right)$, is used. According to Huss and others (2009), the uncertainties of the geodetic mass balance $\left(\sigma_{\text {geod }}\right)$ can be estimated using the following equation:

$$
\sigma_{\overline{\Delta h}}^{2}=\sigma_{\Delta h}^{2} \frac{1}{5} \frac{S_{\text {cor }}}{S}
$$

$$
\sigma_{\mathrm{geod}}=\sqrt{\left(\overline{\Delta h} \sigma_{\rho}\right)^{2}+(\rho \overline{\Delta h})^{2}}
$$

where $S$ is the glacier area, $\overline{\Delta h}$ is the average of glacier-wide elevation changes, $S_{\text {cor }}$ is spatially correlated area and we conservatively estimate $S_{\text {cor }}$ is equal to $S$ (Fischer and others, 2016).

The uncertainties of glaciological mass balance are classified into two parts: random errors and systematic errors in our study and were quantified by std dev. $(\sigma)$ (Thibert and others, 2008). The random errors consist of the accumulation and ablation errors caused by ice and firn as follows.

The accumulation error $\left(\sigma_{\text {accu }}\right)$. Mass-balance processes of UG1 primarily occur in the ablation season. Density is mainly affected by the liquid water at the same time and therefore overestimated. We obtained the firn density $\left(762 \mathrm{~kg} \mathrm{~m}^{-3}\right)$ according to the snow pits observation data from 2012 to 2018. Kelley and others (1994) suggest that density uncertainty is within 5\% resulting in an absolute of 0.03 in our case. The accuracy of accumulation depends on glacier surface roughness and physical properties of the underlying material (Thibert and others, 2008). The difference in underlying material means accumulation will be overestimated when firn is present, and not affected when the underlying material is ice. Considering the temporal and spatial variations of snow depth on glaciers, the final snow depth value $(I=0.78 \mathrm{~m})$ was obtained by averaging the interpolation results over the period $2012-18$ in our study. $\sigma_{\text {accu }}$ can be expressed as follows:

$$
\sigma_{\mathrm{accu}}=\sqrt{\sigma_{\mathrm{rgh}}^{2} d^{2}+\sigma_{\mathrm{d}}^{2} I^{2}}
$$

where firn snow density $(d)$ is $762 \mathrm{~kg} \mathrm{~m}^{-3}$, firn snow density error $\left(\sigma_{\mathrm{d}}^{2}\right)$ is 0.03 and $0.35 \mathrm{~m}$ was adopted as the error on surface 
Table 2. Statistics of accuracy of DEMs and vertical errors between 2012 (RTK-GNSS_DEM), 2015 (TLS_DEM) and 2018 (UAV_DEM)

\begin{tabular}{|c|c|c|c|c|c|c|c|c|c|}
\hline \multirow[b]{2}{*}{ Period } & \multicolumn{2}{|c|}{ Accuracy of DEMs } & \multicolumn{2}{|c|}{$\begin{array}{l}\text { Before correction } \\
\mathrm{m}\end{array}$} & \multicolumn{2}{|c|}{$\begin{array}{l}\text { After correction } \\
\mathrm{m}\end{array}$} & \multirow[b]{2}{*}{$N$} & \multirow{2}{*}{$\begin{array}{l}\mathrm{SE} \\
\mathrm{m}\end{array}$} & \multirow{2}{*}{$\begin{array}{l}E \\
\mathrm{~m}\end{array}$} \\
\hline & $n$ & $\sigma_{\text {DEM }} \mathrm{m}$ & $E_{\mathrm{m}}$ & $E_{\sigma}$ & $E_{\mathrm{m}}$ & $E_{\sigma}$ & & & \\
\hline RTK-GNSS_DEM & 10 & \pm 0.33 & 12.52 & 38.94 & -0.23 & 29.84 & 8090 & 0.59 & 0.41 \\
\hline TLS_DEM & 10 & 0 & 10.65 & 21.83 & 0.75 & 12.68 & 3780 & 0.21 & 0.78 \\
\hline UAV_DEM & 10 & \pm 0.82 & 5.29 & 16.55 & 0.94 & 12.05 & 3780 & 0.19 & 0.96 \\
\hline
\end{tabular}

$N$ is the number of GCPs on off-glacier regions, $\sigma_{\mathrm{DEM}}$ is the uncertainty of the DEMs, $E_{\mathrm{m}}$ is the mean elevation changes on off-glacier regions, $E_{\sigma}$ is the std dev., $\mathrm{SE}$ is the standard error, $E$ is the overall error of the derived surface elevation change and $N$ is the number of considered pixels.
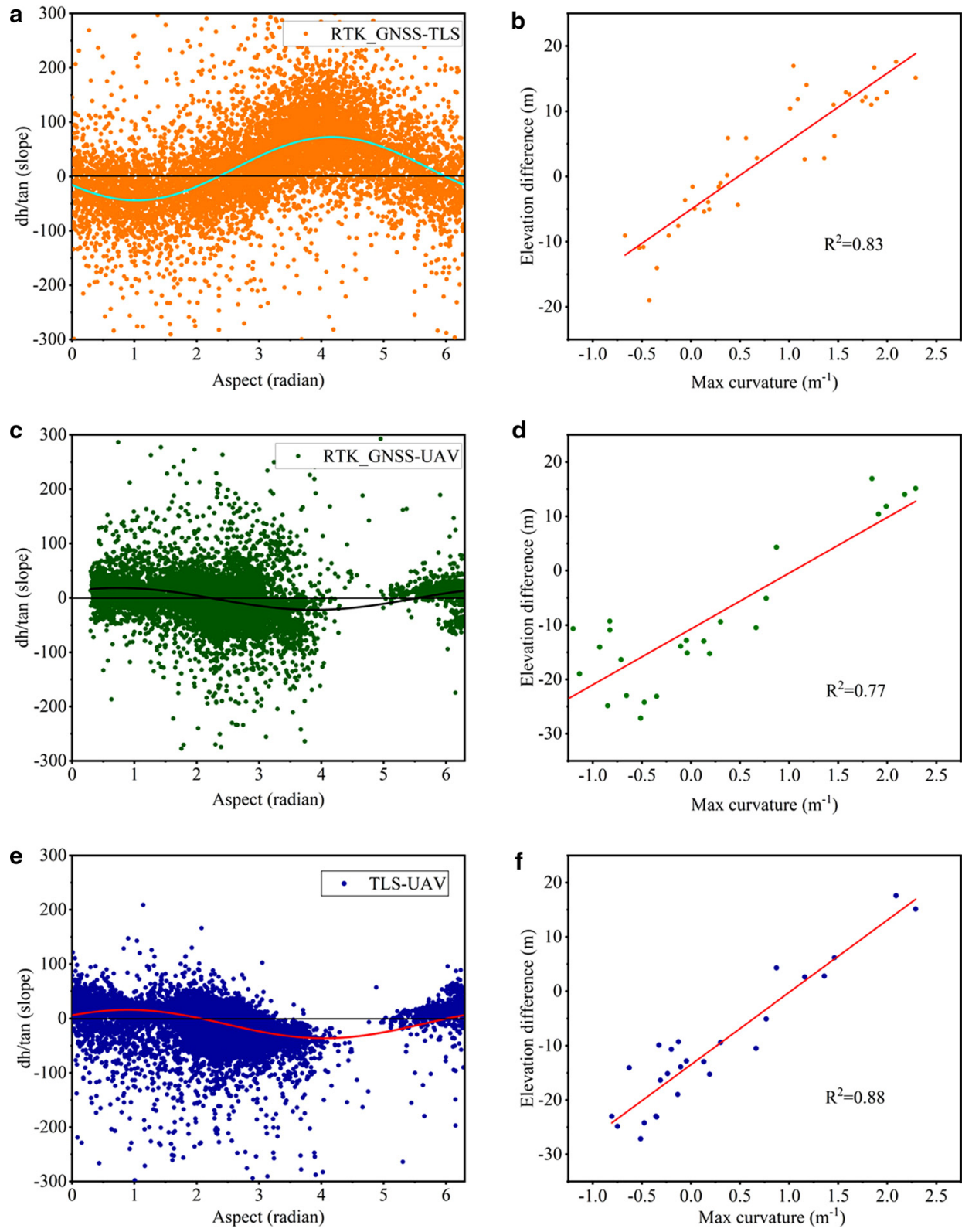

Fig. 3. Scatterplots of (a, c, e) aspect vs slope standardized elevation differences and $(b, d, f)$ maximum curvature vs elevation difference.

roughness $\left(\sigma_{\mathrm{rgh}}^{2}\right)$ (Rees and Arnold, 2006). Finally, the accuracy of accumulation is given as $\pm 0.27 \mathrm{~m}$ w.e. $\mathrm{a}^{-1}$.

The ablation error measured in ice $\left(\sigma_{\text {ice }}\right)$. The error due to the creep of ice was negligible because the observed decrease in ice velocity along the centerline was $3.6 \mathrm{~m} \mathrm{a}^{-1}$ from 1981 to 2012 (Wang and others, 2018). Thus, the inaccurate surface at the bottom of stakes was only directly linked to the uncertainty of ablation measured in ice. Therefore, $\pm 0.14 \mathrm{~m}$ w.e. $\mathrm{a}^{-1}$ was adopted as the uncertainty of ablation measured in ice (Thibert and others, 2008).
The ablation error measured in firn $\left(\sigma_{\text {firn }}\right)$. The error involves stakes being inserted in the underlying ice but emerging from the residual firn of previous year(s) and digging snow pits for massbalance measurements when the snow buried the stakes, respectively. However, the drops of the ablation stakes are limited during the mass-balance measurement and can be difficultly evaluated. The ablation stake is missing when the ablation stake is buried by snow, so there is no digging in the mass-balance measurements. Therefore, uncertainty for ablation measured in firn cannot be determined. 
Table 3. Mean elevation change, mass balance, area and terminus changes during the three periods for UG1

\begin{tabular}{|c|c|c|c|c|}
\hline Location & Items & $2012-15$ & $2015-18$ & $2012-18$ \\
\hline \multirow[t]{4}{*}{ EB } & Elevation change $\left(\mathrm{m} \mathrm{a}^{-1}\right)$ & $-0.63 \pm 0.57$ & $-2.72 \pm 0.95$ & $-1.79 \pm 0.88$ \\
\hline & Mass balance ( $\mathrm{m}$ w.e. $\mathrm{a}^{-1}$ ) & $-0.54 \pm 0.17$ & $-2.31 \pm 0.19$ & $-1.53 \pm 0.19$ \\
\hline & Area change $\left(\mathrm{km}^{2}\right)$ & $-0.03 \pm 0.07 \times 10^{-3}$ & $-0.04 \pm 0.01 \times 10^{-3}$ & $-0.07 \pm 0.07 \times 10^{-3}$ \\
\hline & Terminus change $\left(\mathrm{m} \mathrm{a}^{-1}\right)$ & $-7.83 \pm 0.83$ & $-7.51 \pm 0.16$ & $-7.64 \pm 0.83$ \\
\hline \multirow[t]{4}{*}{ WB } & Elevation change $\left(\mathrm{m} \mathrm{a}^{-1}\right)$ & $-0.94 \pm 0.57$ & $-1.38 \pm 0.95$ & $-0.92 \pm 0.88$ \\
\hline & Mass balance (m w.e. $\left.a^{-1}\right)$ & $-0.79 \pm 0.17$ & $-1.17 \pm 0.18$ & $-0.78 \pm 0.17$ \\
\hline & Area change $\left(\mathrm{km}^{2}\right)$ & $-0.01 \pm 0.07 \times 10^{-3}$ & $-0.01 \pm 0.01 \times 10^{-3}$ & $-0.01 \pm 0.07 \times 10^{-3}$ \\
\hline & Terminus change $\left(\mathrm{m} \mathrm{a}^{-1}\right)$ & $-4.22 \pm 0.83$ & $-5.47 \pm 0.16$ & $-4.93 \pm 0.83$ \\
\hline \multirow[t]{4}{*}{ UG1 } & Elevation change $\left(\mathrm{m} \mathrm{a}^{-1}\right)$ & $-0.83 \pm 0.57$ & $-2.03 \pm 0.95$ & $-1.34 \pm 0.88$ \\
\hline & Mass balance ( $\mathrm{m}$ w.e. $\left.\mathrm{a}^{-1}\right)$ & $-0.71 \pm 0.17$ & $-1.72 \pm 0.19$ & $-1.13 \pm 0.18$ \\
\hline & Area change $\left(\mathrm{km}^{2}\right)$ & $-0.04 \pm 0.07 \times 10^{-3}$ & $-0.04 \pm 0.01 \times 10^{-3}$ & $-0.07 \pm 0.07 \times 10^{-3}$ \\
\hline & Terminus change $\left(\mathrm{m} \mathrm{a}^{-1}\right)$ & $-6.02 \pm 0.83$ & $-6.49 \pm 0.16$ & $-6.28 \pm 0.83$ \\
\hline
\end{tabular}

Sampling error $\left(\sigma_{\text {samp }}\right)$. The sampling error $\sigma_{\text {samp }}$ can be expressed as the ratio between the overall spatial variability of mass balance $\left(\sigma_{\mathrm{sp}}\right)$ and the numbers of ablation stakes $(n)$ as shown in Eqn (10). The $\sigma_{\mathrm{sp}}$ is the ratio of the area occupied by the ablation stakes to the total area of UG1, which was $\sim 80 \%$ according to the mass-balance measurement of UG1. The $n$ was chosen as 44 representing the average number of ablation stakes from 2012 to 2018. This gives a sampling error of \pm 0.12 m w.e. $\mathrm{a}^{-1}$ :

$$
\sigma_{\mathrm{samp}}=\frac{\sigma_{\mathrm{sp}}}{n}
$$

Internal accumulation and ablation. With the traditional stake/ snow pits method, the surface mass balance is measured and measurements of the internal accumulation and internal ablation are always excluded (Østrem and Brugman, 1991). This can lead to annual small but significant systematic cumulative errors. Internal accumulation happens due to re-freezing of water trapped by capillary action in snow and firn by the winter cold (Schneider and Jansson, 2004). Internal ablation is due to ice motion, geothermal heat and water flow. However, systematic errors related to internal accumulation and ablation cannot be quantified due to the lack of corresponding information.

Taking into account the factors mentioned above, the annual uncertainty of glaciological mass balance $\left(\sigma_{\text {glac }}\right)$ is therefore $\pm 0.32 \mathrm{~m}$ w.e. $\mathrm{a}^{-1}$ without considering the systematic uncertainties. The cumulative uncertainty of glaciological mass balance is \pm 1.92 m w.e. for the period from 2012 to 2018 :

$$
\sigma_{\mathrm{glac}}=\sqrt{\left(\sigma_{\mathrm{accu}}\right)^{2}+\left(\sigma_{\mathrm{ice}}\right)^{2}+\left(\sigma_{\mathrm{firn}}\right)^{2}+\left(\sigma_{\mathrm{samp}}\right)^{2}}
$$

\subsection{Differencing DEM quality}

The survey accuracy about RTK-GNSS can reach the resolution in centimeters, and glacier surface elevation was obtained through dense points coverage. Zhang and others (2017) extracted the surface elevation of DinSAR_DEM and RTK-GNSS_DEM at individual ablation stakes. The results show that the correlation coefficient between them is 0.6 and the RTK-GNSS_DEM surface elevation is greater than the DinSAR_DEM surface elevation (Zhang and others, 2017). Moreover, RTK-GNSS_DEM may be affected by its survey points' density. The survey points are sparse at the upper area and lower tongue of the glacier because of the steep terrain causing the difficulty in arriving.

For TLS scanning, the visual angles of scanning location and atmospheric conditions are important factors to obtain highquality point cloud data. Dry and windless weather conditions are a prerequisite for high-quality data collection. There was no precipitation and little wind speed before noon at UG1. In the cloudy sky around the glacier, in order to obtain high-quality point cloud data, we have to set up multiple scanning positions to scan the surface area of the glacier as much as possible. In our fieldwork, the overlap percentage of point clouds in the four scanning positions exceeds $30 \%$ covering the entire glacier. Although the scanning positions are limited in this study, we can find the best visual angles to get the maximum scanning range. Ideally, in order to obtain better visual angles, the distribution of scanning positions should be located in different elevation bands and directions. However, it is not always easy to access the higher parts to set up the instruments. Overall, the point cloud data and TLS_DEM obtained by TLS scanning in this study can meet the requirement for monitoring UG1.

The uncertainty of DEM differencing was derived from systematic shifts of DEMs in the horizontal and vertical directions (Nuth and others, 2011). The mean uncertainty of glacier surface elevation changes was $\pm 0.71 \mathrm{~m}$ (Table 2), indicating that elevation differences in the off-glacier regions had stabilized after these adjustments and the DEM differencing is encouraging.

\section{Results}

The RTK-GNSS survey in 2012 and the TLS survey in 2015 were conducted for the whole UG1, whereas the UAV survey in 2018 was concentrated in the glacier tongue covering the elevation from 4150 to $4300 \mathrm{~m}$ a.s.l. for the WB and from 3743 to 4000 $\mathrm{m}$ a.s.l. for the EB, respectively. Therefore, the glacier elevation changes are studied in this elevation range for the periods 2015-18 and 2012-18.

\subsection{Area change}

The area of UG1 was $1.59 \mathrm{~km}^{2}$ in $2012,1.55 \mathrm{~km}^{2}$ in 2015 and 1.52 $\mathrm{km}^{2}$ in 2018 , respectively. The glacier area has shrunk by $0.07 \pm$ $0.07 \times 10^{-3} \mathrm{~km}^{2}$ between 2012 and 2018 (Table 3). Combined with the area of 1962-2012, it was found that the area of UG1 reduced by $3.87 \%$ from 1962 to 2018 (Fig. 4a). The area reduced by $\sim 0.32 \%$ in $1962-73,0.23 \%$ in $1973-86,0.78 \%$ in $1986-2000$, $1.21 \%$ in $2000-12$ and $1.33 \%$ in $2012-18$, respectively. Overall area reduction demonstrated an increasing and then decreasing trend before 1986 and afterward kept increasing continuously. One possible reason is that the annual temperature played a most important role in this period (Wang and others, 2016). Although the period between 2012 and 2018 was less than a decade, the area loss was markedly higher than during the earlier periods of 1962-73 and 1973-86. In the future, the glacier area shrinkage will probably be continued under the current climate change by analyzing the previous change trend. 

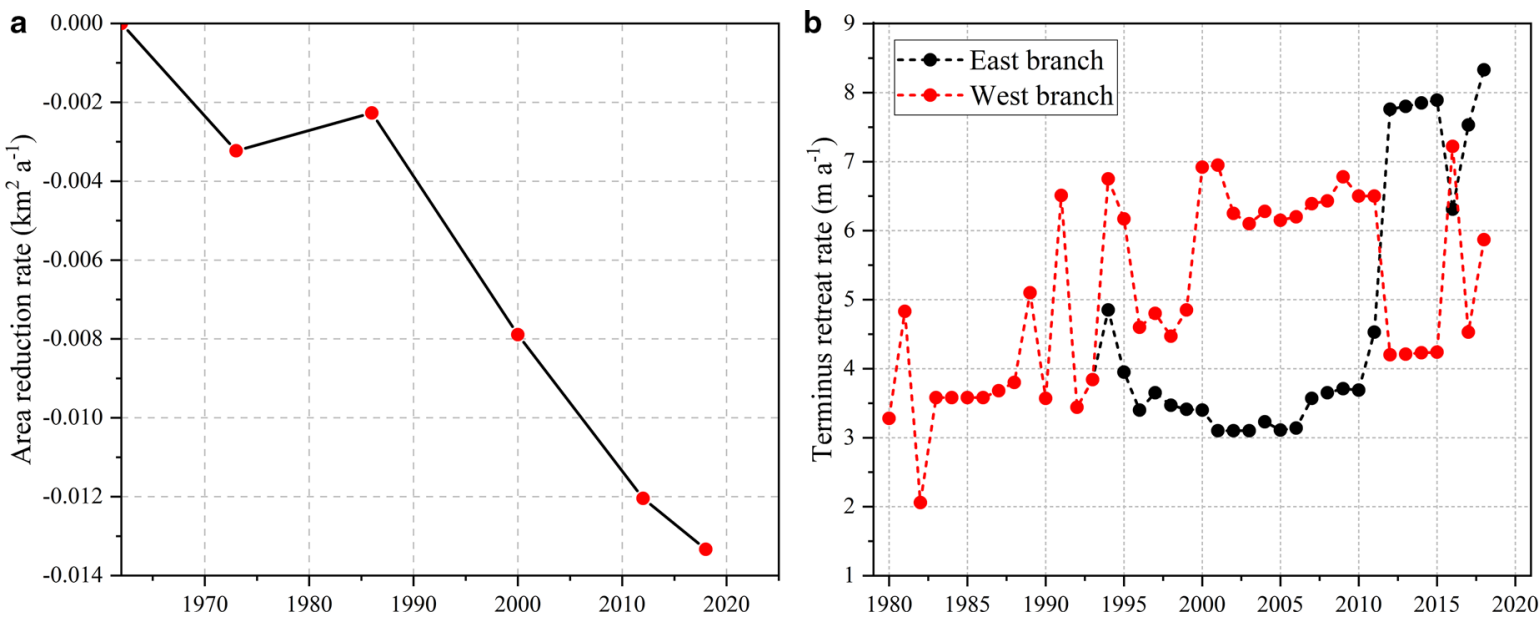

Fig. 4. Glacier area reduction rate for different periods between 1962 and 2018 (a). Terminus retreat rate of EB and WB during $1980-2018$ (b).

\subsection{Terminus change}

As shown in Table 3 and Figure $4 \mathrm{~b}$, the terminus retreat rate of UG1 was $6.28 \pm 0.83 \mathrm{~m} \mathrm{a}^{-1}$ during 2012-18. The retreat rate was $7.64 \pm 0.83$ and $4.93 \pm 0.83 \mathrm{~m} \mathrm{a}^{-1}$ for the EB and WB, respectively. Compared with the rate during 2012-15 $\left(6.02 \pm 0.83 \mathrm{~m} \mathrm{a}^{-1}\right)$, the terminus retreat accelerated during 2015-18 $\left(6.49 \pm 0.16 \mathrm{~m} \mathrm{a}^{-1}\right)$. The terminus retreat rate of EB for the period 2012-18 was greater than that of WB. Comparing with the previous studies about glacier terminus change (Wang and others, 2016), it is found that the terminus retreat rate was $3.89 \mathrm{~m} \mathrm{a}^{-1}$ during 1980-93 before the glacier separated and then continued to retreat during 1994-2018. There are two obvious terminus retreat stages: during 1994-2011, the overall terminus retreat rate was $4.81 \mathrm{~m} \mathrm{a}^{-1}$, with the WB terminus retreat rate $\left(6.06 \mathrm{~m} \mathrm{a}^{-1}\right)$ larger than that of $\mathrm{EB}\left(3.56 \mathrm{~m} \mathrm{a}^{-1}\right)$. The terminus retreat rate during 2012-18 $\left(6.28 \pm 0.83 \mathrm{~m} \mathrm{a}^{-1}\right)$ was significantly larger than the former $\left(4.81 \mathrm{~m} \mathrm{a}^{-1}\right)$.

The difference in glacier terminus changes for the EB and WB was determined not only by mass balance but also glacier dynamics (Li and others, 2011). For example, the terminus retreat rate coincided with the thinning rate during 2012-18 (see Section 4.3). Second, the glacier tongue of $\mathrm{WB}$ has a slope orientation of southeast, and the EB is sheltered by a mountain headwall. The inter-annual variation of the ice velocity is known to act on the terminus. It is shown that the ice velocity of the EB after 2012 is significantly lower than that of WB (Wang and others, 2018). The combination of these factors may lead to that the $\mathrm{WB}$ retreat rate is greater than that of the $\mathrm{EB}$ only under the scenario of the same climate condition.

\subsection{Surface elevation and mass balance}

Figure 5 shows the glacier surface elevation changes for UG1 during 2012-18. Distributed elevation change patterns are generally similar for three periods characterized by thinning in the glacier tongues. Comparing to the glacier tongue during 2012-15, surface lowering was greater during 2015-18. EB mass loss was smaller during 201215 , and afterward greater during 2015-18, this may be related to the slope and direction and the accumulation area of EB. The EB mass loss in glacier tongue was greater than that of WB during 2015-18. Table 3 shows mean glacier surface elevation changes and specific mass change rates for three periods, the mass change rate of EB generally was about twice as much as the WB.

Figure 6 shows mass balance vs altitude of UG1, with histograms and polyline representing glacier area and mass balance in different altitude intervals, respectively. The mass-balance elevation distribution remained similar; specific mass balance increased with rising altitude. EB with the altitude above $4200 \mathrm{~m}$ a.s.l. showed a slightly decreasing accumulation, which may be associated with glacier dynamics. Mass balance and vertical black line met where the glacier mass balance was close to the equilibrium-line altitude in 2012-15; the corresponding altitudes of the EB and WB were 3950 and $4025 \mathrm{~m}$ a.s.l., respectively. Based on the geodetic mass balance derived from TLS (Xu and others, 2019), the equilibrium-line altitudes of UG1 in 2015-18 will shift: the equilibrium-line altitudes of EB may change little and the equilibrium-line altitudes of WB will rise. Although glacier extent in 2015-18 and 2012-18 was concentrated in the glacier tongue and resulting mass-balance change with elevation was incomplete, mass balance increased with rising altitude is obvious (Figs $6 c, d, e, f$ ).

\section{Discussion}

\subsection{Comparison of geodetic and glaciological mass balances}

Geodetic mass balance of UG1 was previously calculated from 1981 to 2009, and the difference between the geodetic and glaciological mass balance was $<10 \%$ (Wang and others, 2014). In order to calculate the statistical significance between the geodetic and glaciological mass balances, and validate the geodetic against the glaciological mass balance, Zemp and others (2013, Eqns $19-21)$ defined the reduced discrepancy $(\delta)$ as the closer the reduced discrepancy is to zero if the geodetic and glaciological mass balances is more consistent. The values of $\delta$ range from 0.03 to 0.22 . As $\delta$ falls within the $95 \%(|\delta|<1.96)$ confidence intervals, the agreement between the geodetic and glaciological mass balances can be considered satisfactory as shown in Table 4. A calibration of the glaciological mass-balance record is therefore currently not necessary.

However, the UAV survey in 2018 was only concentrated in the glacier tongue. Therefore, the specific mass balances measured at individual ablation stakes in the glacier tongue were utilized for a comparison with the geodetic specific mass balances at the corresponding locations for the period from 1 September 2012 to 24 April 2018, and 25 April 2015 to 24 April 2018. The glaciological specific mass balance matched geodetic specific mass balance (Fig. 7). The correlation coefficients $\left(R^{2}\right)$ between the glaciological specific mass balance and geodetic specific mass balance were $>0.88$, and the RMSEs were between 0.70 and $1.32 \mathrm{~m}$ w.e. $\mathrm{a}^{-1}$.

\subsection{Accuracy of geodetic and glaciological mass balance}

The quality of geodetic mass balances relies on the accuracy of glacier surface elevation changes and density conversion of 

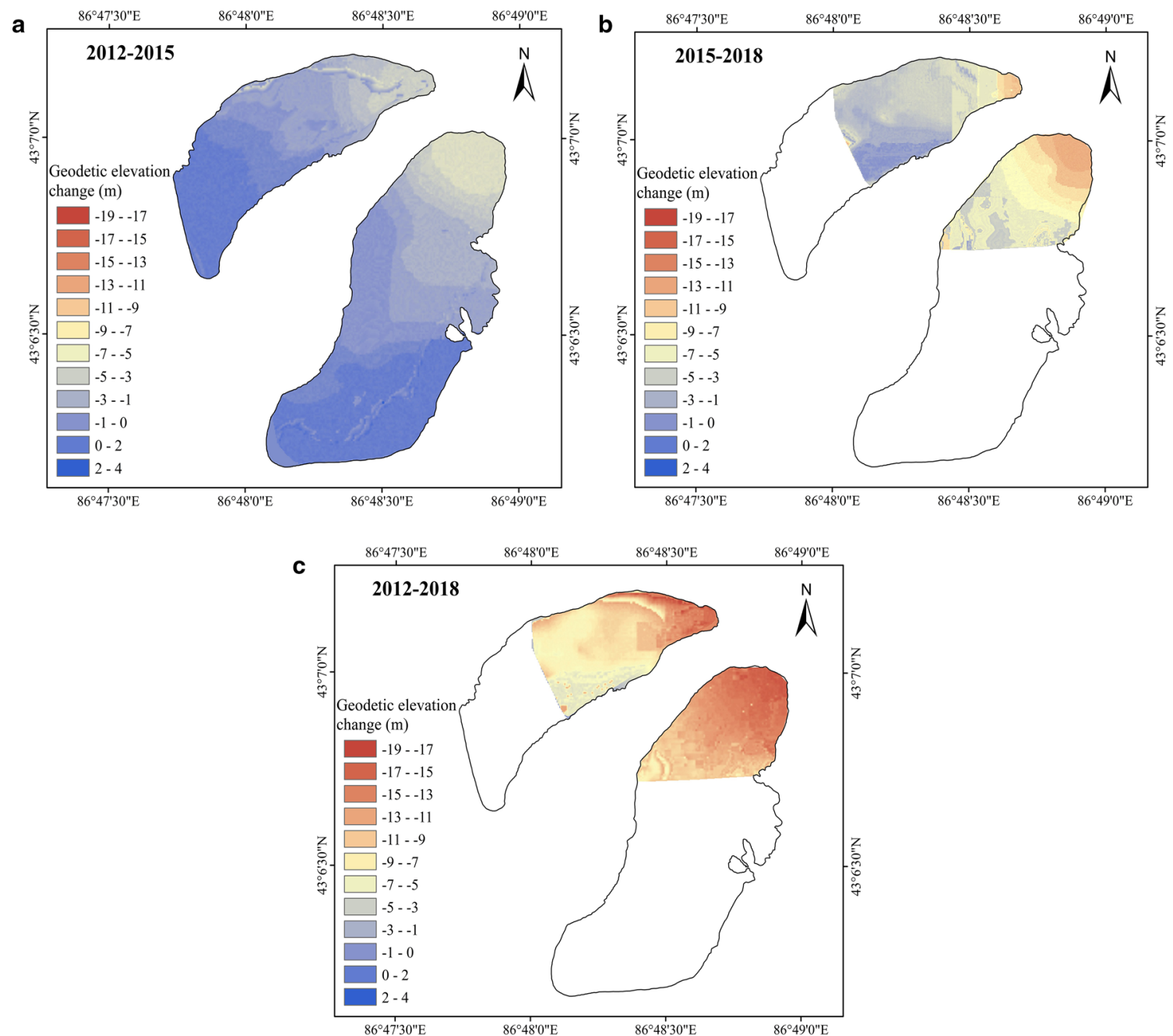

Fig. 5. Surface elevation changes of UG1 from 2012 to 2018. The boundary in (a) is from boundary 2015 in Figure 2; boundaries in (b) and (c) are the same as boundary 2018 in Figure 2.

volume-to-mass changes. With regard to density conversion, this study used $850 \pm 60 \mathrm{~kg} \mathrm{~m}^{-3}$ recommended by Huss (2013). Calculated uncertainties in the geodetic mass balances ranged from \pm 0.17 to $\pm 0.19 \mathrm{~m}$ w.e. $\mathrm{a}^{-1}$, with an average value of \pm 0.17 $\mathrm{m}$ w.e. $\mathrm{a}^{-1}$ for the investigated periods (Table 3 ). This may be related to differencing DEM quality (see Section 3.5) and system error in three techniques' survey (multiple scan positions and a larger scanning range, flight altitude).

The uncertainty of mass-balance measurements was $\pm 0.32 \mathrm{~m}$ w.e. $\mathrm{a}^{-1}$ during 2012-18, which is greater than that of previous studies probably due to more comprehensive determination of the ablation error measured in ice and firn in our study (Wang and others, 2014; Xu and others, 2019). Nonetheless, comparison of geodetic and glaciological mass balances can be considered satisfactory (see Section 5.1).

\subsection{The relationship between the surface elevation, area and terminus changes}

The cumulative change rate as an index can be used to analyze the relationship between the surface elevation, area and terminus. The cumulative change rates of surface elevation, area and terminus during 1962-2018 are shown in Figure 8. UG1 experienced terminus retreating and thinning, however, the decreasing rate of different periods showed differences. In the period 1962-81, area reduction rate was consistent with terminus retreat rate except for the surface elevation thinning rate. The area reduction rate $(5.7 \%)$ and terminus retreat rate $(4.9 \%)$ were still larger than the surface elevation thinning rate (1.4\%) during 1981-86. From 1986 to 2001, the surface elevation thinning rate was the same as the terminus retreat rate, and was smaller than the area reduction rate. From 2001 to 2006, the surface elevation thinning rate increased significantly compared with the terminus retreat rate, and exceeded the area reduction rate after 2012. Although we did not obtain the whole surface elevation thinning rate of UG1 for the period 2015-18 in this study, Li (2010) used the modified glacier dynamic models to predict the future changes of UG1, showing that the surface elevation thinning rate will be larger than the area reduction and terminus retreat rate before 2100 assuming that the future climate will remain unchanged. Although the surface thinning rate in 1961-81 is almost not changing, the glacier surface elevation thinning mainly contributed to glacier change in 1961-2018, and it was the largest contributor to local mass change especially in the long term.

The area change and the terminus change start to diverge since 1981: the terminus retreat rate is less than the area reduction rate (Fig. 8). The surface elevation change determines glacier retreat or thinning. Since UG1 is in the U valley below $3880 \mathrm{~m}$ a.s.l., and the ice is concentrated, the terminus retreat rate was relatively small until UG1 retreated to the altitude of $3880 \mathrm{~m}$ a.s.l. (Li, 2010). Glacier mass balance (glacier surface elevation) is the most direct response to climate change. There was a delay and a response time 

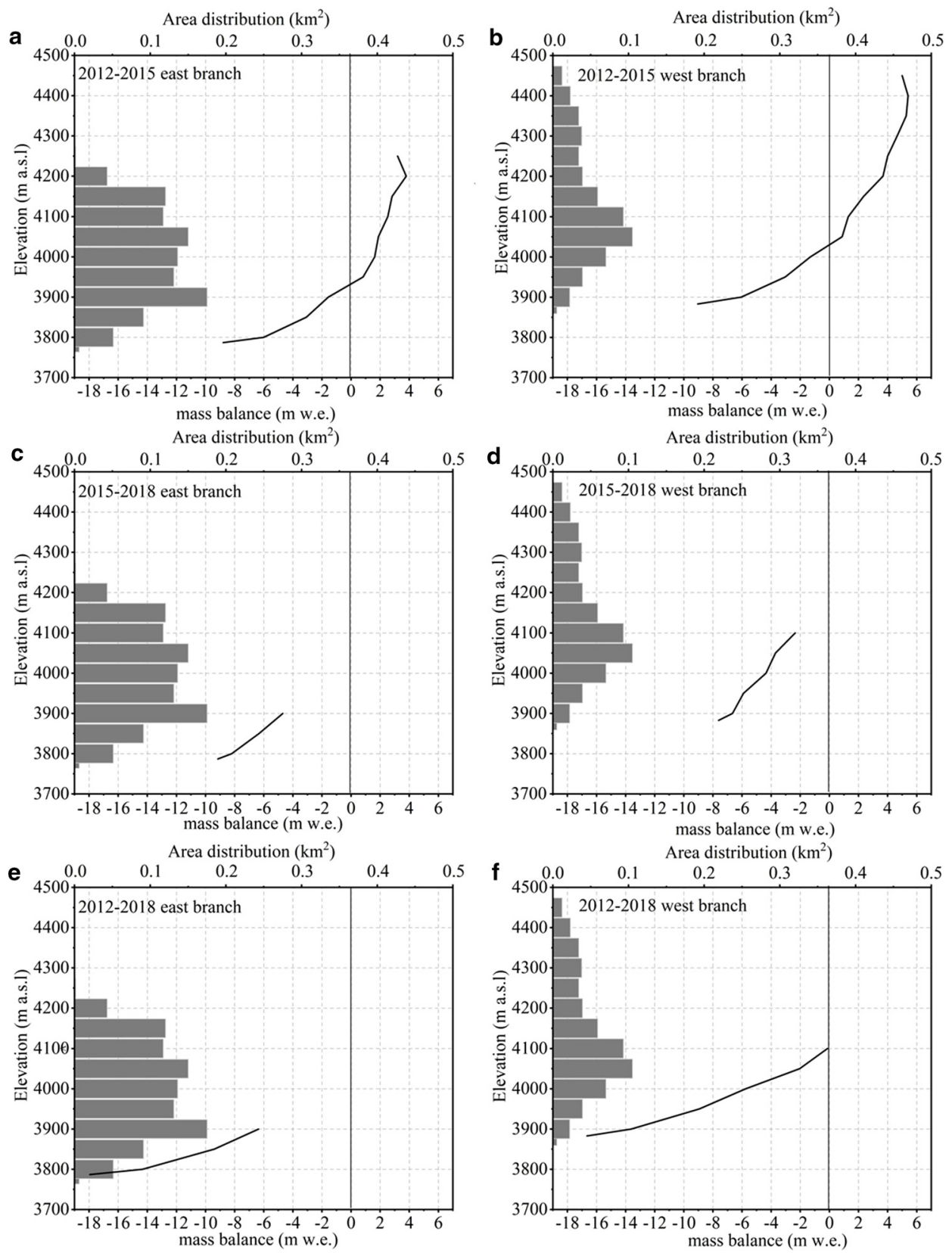

Fig. 6. Geodetic mass-balance change with elevation. Gray horizontal bars indicate the areaelevation distribution of UG1. Vertical black line represents the equilibrium-line altitude. Note that the glacier extent in 2015-18 and 2012-18 was concentrated in the glacier tongue and massbalance change with elevation was incomplete. Altitude is obtained from the DEM which is obtained from RTK-GNSS, TLS and UAV with the resolution of $5 \mathrm{~m}$. The glacier outlines are based on the glacier boundary of 2015 and 2018.

Table 4. Geodetic mass balance $\left(B_{\text {geod }}\right)$ with its uncertainty $\left(\sigma_{\text {geod }}\right)$ and glaciological mass balance ( $\left.B_{\text {glac }}\right)$ with its uncertainty $\left(\sigma_{\text {glac }}\right)$ of UG1 for the given time periods

\begin{tabular}{llllll}
\hline Period & $\begin{array}{c}B_{\text {geod }} \\
\text { m w.e. }\end{array}$ & $\begin{array}{l}\sigma_{\text {geod }} \\
\text { m w.e. }\end{array}$ & $\begin{array}{c}B_{\text {glac }} \\
\text { m w.e. }\end{array}$ & $\begin{array}{l}\sigma_{\text {glac }} \\
\text { m w.e. }\end{array}$ & $\delta$ \\
\hline $\begin{array}{l}\text { 1 September 2012-25 } \\
\text { April 2015 }\end{array}$ & & & & \\
$\begin{array}{l}\text { (whole glacier) } \\
\text { UG1 }\end{array}-2.13$ & \pm 0.51 & -2.07 & \pm 0.96 & 0.05 \\
EB & -1.62 & \pm 0.51 & -1.58 & \pm 0.96 & 0.03 \\
WB & -2.37 & \pm 0.51 & -2.13 & \pm 0.96 & 0.22 \\
25 April 2015-24 April 2018 & & & & \\
(glacier tongue) & & & & \\
UG1 & -5.16 & \pm 0.57 & -5.01 & \pm 0.96 & 0.13 \\
EB & -6.93 & \pm 0.57 & -6.83 & \pm 0.96 & 0.08 \\
WB & -3.51 & \pm 0.54 & -3.45 & \pm 0.96 & 0.05 \\
\hline
\end{tabular}

$\delta$ is the reduced discrepancy.

of terminus change to a mass-balance disturbance caused by climate change (Paterson, 1994), probably resulting in surface elevation thinning while the terminus remained relatively stable.

\subsection{Potential of the RTK-GNSS, TLS and UAV applied in glacier change monitoring}

This study presents the application of three technologies in monitoring the change of UG1. The cross application of RTK-GNSS, TLS and UAV technology in glacier change can not only complement each other's advantages, but also provide more accurate results of glacier change (Fig. 9). The greatest strength of the TLS is the long-range scanning, which allows most of the glacier surface to be measured, especially in the upper steep area of the glacier. The geodetic mass balance based on the TLS in the upper steep area is well consistent with the glaciological mass balance (Xu and others, 2019; Fig. 7). The UAV at relatively low cost is suited to the study of mountain glaciers where steep topography, frequent cloud cover, surface heterogeneity and generally smaller glacier size can limit the use of satellite imagery (Wigmore and Mark, 2017). UAV can also conduct glacier surface surveys at weekly, daily and even diurnal scales, which can provide unique insights into glacier processes and, is almost impossible to be obtained by TLS and RTK-GNSS. TLS and UAV are able to accurately survey potentially dangerous areas on glacier surfaces 

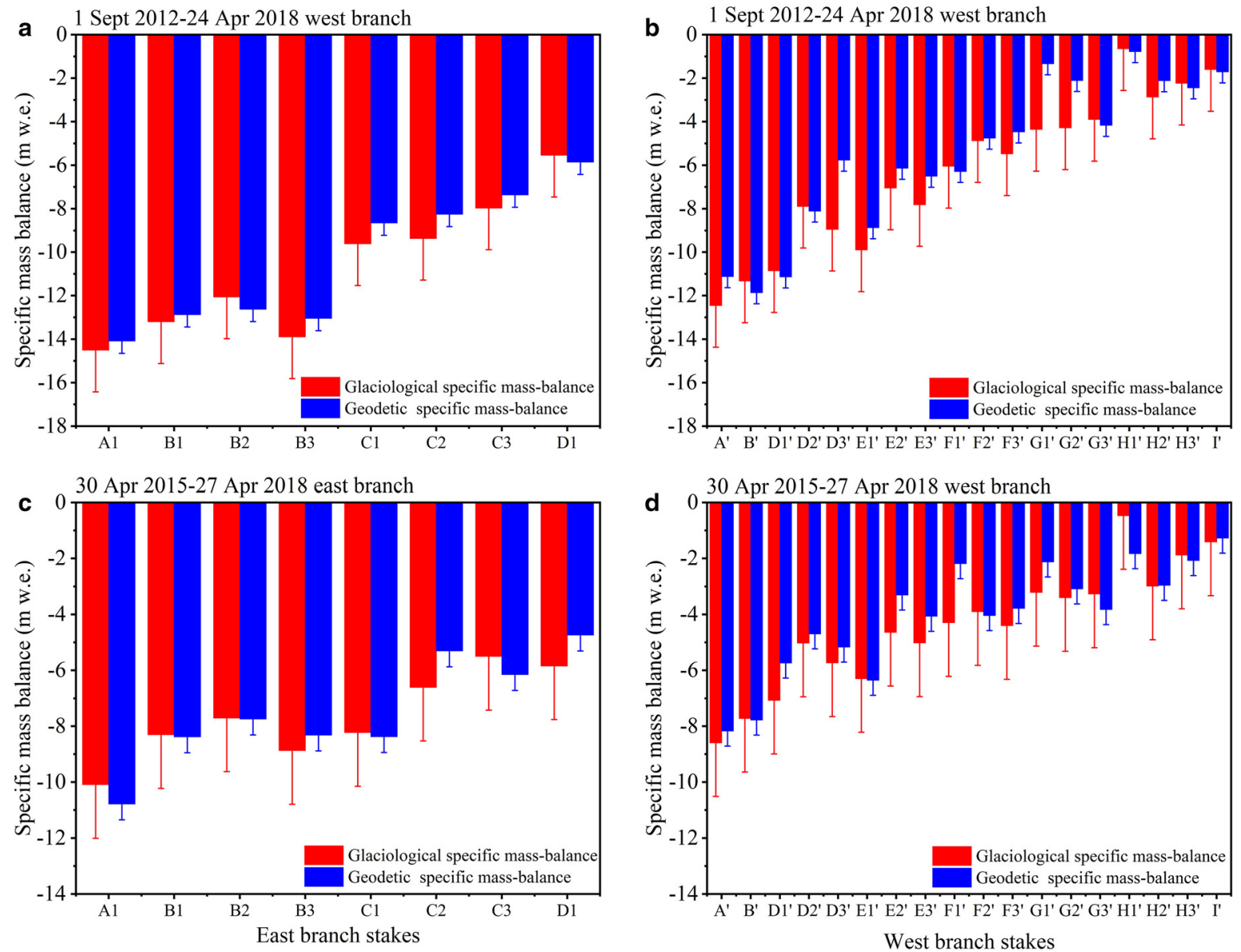

Fig. 7. Comparison between glaciological and geodetic specific mass balance for the period from 1 September 2012 to 24 April 2018 and from 25 April 2015 to 24 April 2018; red and blue error bars represent glaciological and geodetic specific mass-balance errors. The horizontal axis represents the serial numbers of the ablation stakes as shown in Figure $1 \mathrm{~b}$.

Fig. 8. Relationship between the surface elevation, area and terminus change rate of UG1 in the different periods. Note that cumulative change rates from 1962 to 2006 are derived using data from Wang (2011). No value of surface elevation thinning rate in 2015-18 was due to incomplete UAV_DEM (Fig. 1c).

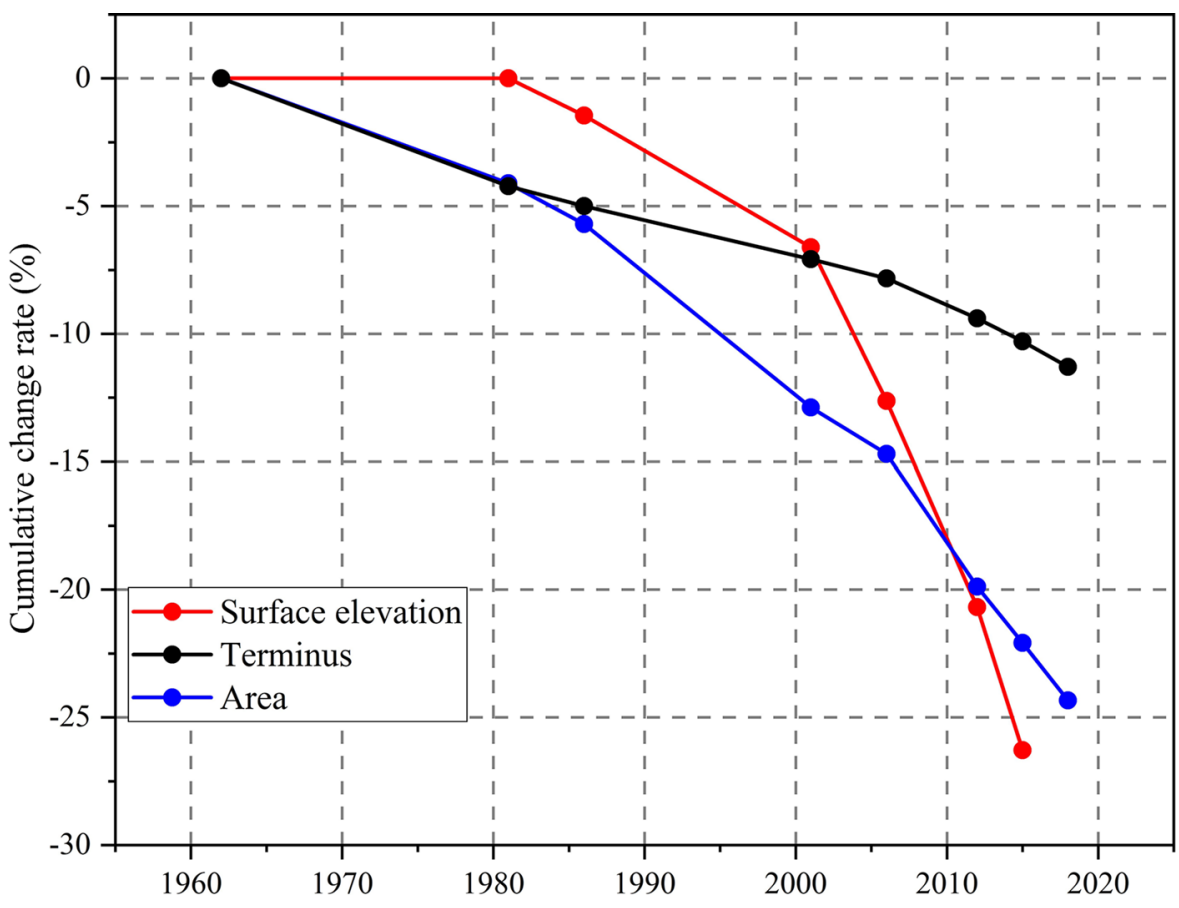

(such as avalanche paths) regardless of topography compared to the RTK-GNSS.

Nevertheless, there are a few significant limitations of the TLS and UAV. It is a great challenge for a broader application of TLS measurement and point cloud data post-processing. Besides the need of specific knowledge, skills and experience for data processing, TLS survey requires that good glacier surface visual angles can be obtained at suitable scanning positions, which can be multi- 


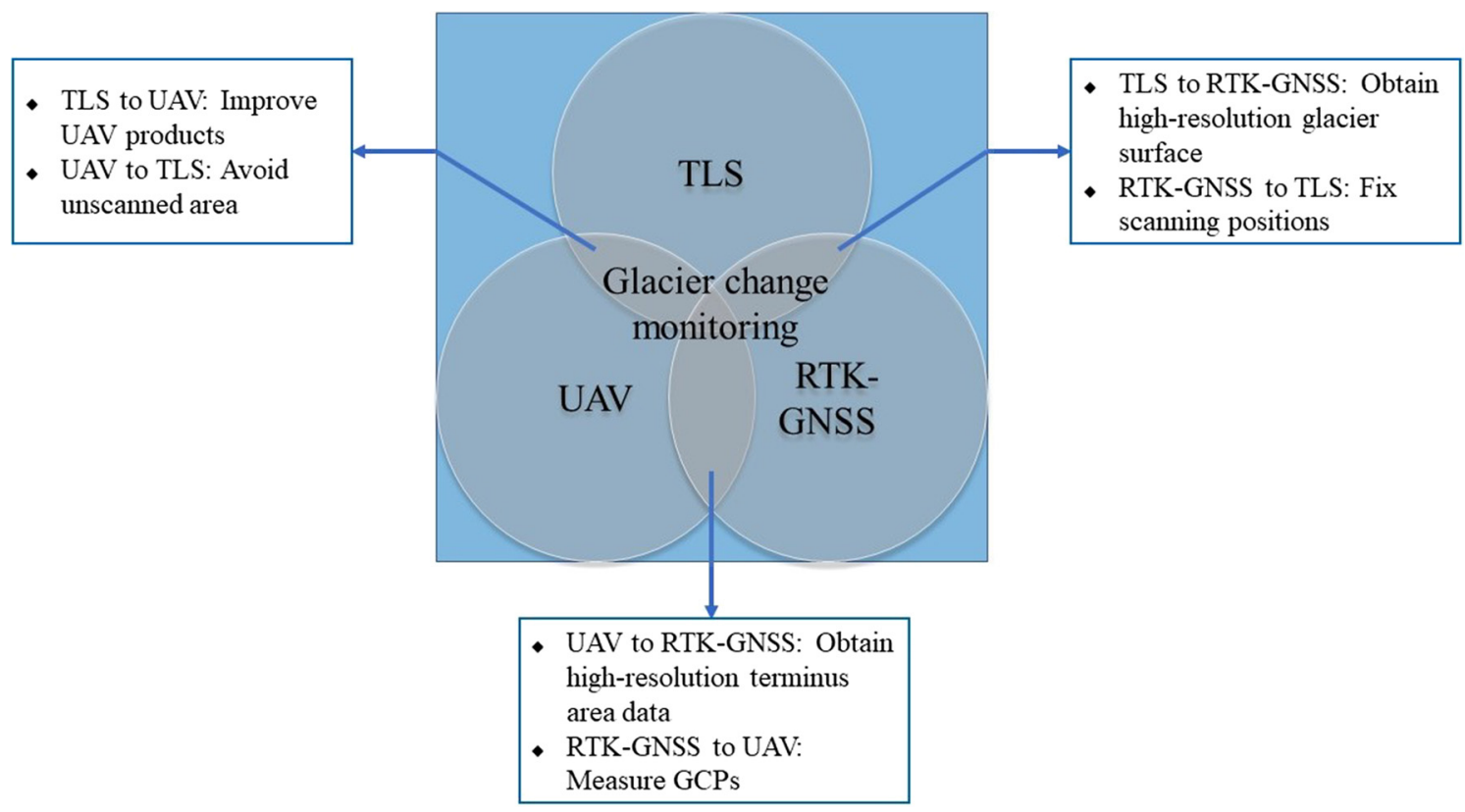

Fig. 9. Potential for TLS, UAV and RTK-GNSS interaction in glacier change monitoring. The boxes with text indicate that when the two techniques are used for glacier monitoring at the same time, the two techniques can complement each other.

temporally registered with multiple scans for change detection. Sometimes, unscanned areas may appear during TLS surveys. TLS is also very expensive in the initial costs of the scanner and software license compared to the UAV (Fischer and others, 2016). UAV has problems of covering a meaningful area and the uneven distribution of GCPs in off-glacier regions that can lead to distortion of UAV products. Additionally, installing GCPs in off-glacier regions requires a lot of labor and is very dangerous in many cases. The error generated by UAV survey can be reduced by the installation and survey of GCPs and the survey design (Immerzeel and others, 2014; Wigmore and Mark, 2017). RTK-GNSS has a limited survey points' density, which are sparse in the upper area and the glacier tongue because of the steep terrain resulting in difficult access. However, it is difficult to evaluate quality of the DEMs because the three survey technologies have not been carried out at the same time until now.

According to the second Chinese Glacier Inventory dataset, $83 \%$ of the total number of glaciers in western China are small glaciers such as UG1 (Guo and others, 2015). The RTK-GNSS, TLS and UAV monitoring has large potential for glacier change monitoring in western China. UAV has the potential to avoid unscanned areas in TLS survey and using RTK-GNSS fixed scanning positions can ensure consistent and good glacier surface visual angles in TLS survey. Since UAV survey also has the problem of only covering a meaningful area, we can compare the TLS and UAV products at the same time to improve the accuracy of the glacier surface elevation. To minimize distortions of UAV products the GCPs in off-glacier regions should be as evenly distributed as possible and measured by RTK-GNSS. This suggests that RTK-GNSS is critical for the TLS and UAV survey. The integration of TLS or UAV can compensate the RTK-GNSS limitation in the glacier upper area and the glacier tongue.

In future research, we plan to simultaneously use all three survey technologies to monitor the glacier at a specific time. Since UG1 has continuous observation conditions and then sufficient measurement verification data (i.e. mass balance and surface velocity) can be obtained. Additionally, Landsat images' extraction surface temperature can also be used to validate UAV results. Hence, RTK-GNSS, TLS and UAV have great potential to quantify seasonal and annual glacier changes in the future and our approach yields insight into the smaller-scale temporal and spatial changes in glacier area, terminus and surface elevation.

\section{Conclusions}

In this study, RTK-GNSS, TLS and UAV surveys were conducted over UG1 in 2012, 2015 and 2018 to obtain DEMs, respectively. Three high-resolution DEMs were used to calculate area, terminus and surface elevation changes and geodetic mass balances over different periods. The statistical analysis shows that the geodetic specific mass balance was in good agreement with the glaciological specific mass balance $\left(R^{2} \geqslant 0.88\right)$, although the geodetic results were slightly positive. UG1 has experienced an accelerated recession during the period of 2012-18. Surface elevation has reduced $0.83 \pm 0.57 \mathrm{~m}$ w.e. $\mathrm{a}^{-1}$ for $2012-15$, and glacier tongue surface elevation has also reduced $2.03 \pm 0.95$ and $1.34 \pm 0.88 \mathrm{~m}$ w.e. $\mathrm{a}^{-1}$ for $2015-18$ and $2012-18$, respectively. Glacier area had shrunk by $0.07 \pm 0.07 \times 10^{-3} \mathrm{~km}^{2}$ during $2012-18$, with a rate of $0.01 \pm 0.01 \mathrm{~km}^{2} \mathrm{a}^{-1}$. The glacier terminus retreat rate was $6.28 \pm$ $0.83 \mathrm{~m} \mathrm{a}^{-1}$, with retreat rates of $\mathrm{EB}$ and $\mathrm{WB}$ being $7.64 \pm 0.83$ and $4.93 \pm 0.83 \mathrm{~m} \mathrm{a}^{-1}$, respectively.

This paper studied the application of RTK-GNSS, TLS and UAV in the monitoring of glacier changes. It is found that the three technologies have potential advantages, including (1) TLS allows most of the glacier surface to be measured due to its longrange scanning capabilities, (2) UAV with relatively low cost can conduct glacier surface surveys at weekly, daily and even diurnal scales and (3) it is strongly recommended that the TLS scan positions and UAV GCPs in off-glacier regions were surveyed using the RTK-GNSS to assure the accuracy of direct georeferencing and registration. However, limitations also existed for the three technologies: (1) choosing the suitable and stable scan positions was difficult for the TLS survey, (2) uneven distribution of GCPs in off-glacier regions can lead to distortion of UAV products and (3) survey points in the upper area and the glacier tongue were sparse during the RTK-GNSS survey. At present, we have conducted RTK-GNSS, TLS and UAV surveys to monitor UG1, and found complementary advantages between all three methods. This is especially relevant for the widely distributed small glaciers in western China similar to UG1. The combined 
application of RTK-GNSS, TLS and UAV has great potential for development in the future.

Acknowledgements. This research was jointly funded by the National Natural Science Foundation of China (no. 41771077), the Funds for Creative Research Groups of China (no. 41421061), the Youth Innovation Promotion Association of CAS, the National Natural Science Foundation of China (no. 42001067), the Strategic Priority Research Program of Chinese Academy of Sciences (no. XDA20020102) and the State Key Laboratory of Cryospheric Science (no. SKLCS-ZZ-2020). Additionally, the authors thank the editor Argha Banerjee and referees for their numerous invaluable comments in improving the paper.

\section{References}

Andreassen LM, Elvehøy H and Kjøllmoen B (2005) Glacier mass-balance and length variation in Norway. Annals of Glaciology 42(1), 317-325. doi: $10.3189 / 172756405781812826$

Besl PJ and Mckay HD (1992) A method for registration of 3-D shapes. IEEE Transactions on Pattern Analysis \& Machine Intelligence 14(2), 239-256. doi: 10.1109/34.121791.

Bhardwaj A, Sam L, Akanksha M-TFJ and Kumar R (2016) UAVs as remote sensing platform in glaciology: present applications and future prospects. Remote Sensing of Environment 175, 196-204. doi: 10.1016/j.rse.2015. 12.029

Brun F, Berthier E, Wagnon P, Kääb A and Treichler D (2017) A spatially resolved estimate of High Mountain Asia glacier mass balances from 2000 to 2016. Nature Geoscience 10(9), 668-673. doi: 10.1038/ngeo2999

Che YJ, Wang SY and Liu J (2019) Application of unmanned aerial vehicle (UAV) in the glacier region with complex terrain: a case study in Baishui River Glacier No. 1 located in the Yulong Snow Mountains. Journal of Glaciology and Geocryology 41(1), 1-9. doi: 10.7522/j.issn.1000-0240. 2019.0002

Deng HJ and Chen YN (2018) The glacier and snow variations and their impact on water resources in mountain regions: a case study in Tianshan Mountains of Central Asia. Acta Geographica Sinica 73(7), 1309-1323. doi: $10.11821 / \mathrm{dlxb} 201807010$

Ding X, Ai ST, Wang ZM, Hao WF and Tan Z (2019) Study on surface elevation changes of Arctic Glacier Austre Lovénbreen using RTK-GNSS. Chinese Journal of Polar Research 31(3), 246-257.

Farinotti D and 7 others (2015) Substantial glacier mass loss in the Tien Shan over the past 50 years. Nature Geoscience 8(9), 716-722. doi: 10.1038/ ngeo 2513

Fischer M, Huss M, Kummert $\mathbf{M}$ and Hoelzle $\mathbf{M}$ (2016) Application and validation of long-range terrestrial laser scanning to monitor the mass balance of very small glaciers in the Swiss Alps. The Cryosphere 10, 1279-1295. doi: 10.5194/tc-10-1279-2016

Gabbud C, Micheletti N and Lane SN (2015) Lidar measurement of surface melt for a temperate Alpine Glacier at the seasonal and hourly scales. Journal of Glaciology 61, 963-974. doi: 10.3189/2015jog14j226

Gardelle J, Berthier E and Arnaud Y (2012) Impact of resolution and radar penetration on glacier elevation changes computed from DEM differencing. Journal of Glaciology 58(208), 419-422. doi: 10.3189/2012JoG11J175

Gardner A and 15 others (2013) A reconciled estimate of glacier contributions to sea level rise: 2003 to 2009. Science (New York, N.Y.) 340, 852857. doi: $10.1126 /$ science. 1234532 .

Guo WQ and 10 others (2015) The second Chinese glacier inventory: data, methods and results, Journal of Glaciology, 61, 357-372. doi:10.3189/ 2015JoG14J209.

Hall DK, Bayr KJ, Schöner W, Bindschadler EA and Chien JYL (2003) Consideration of the errors inherent in mapping historical glacier positions in Austria from the ground and space (1893-2001). Remote Sensing of Environment 86(4), 566-577. doi: 10.1016/S0034-4257(03)00134-2

Hock R and 14 others (2019) High mountain areas. In Kaser G and Mukherji A (eds), IPCC Special Report on the Ocean and Cryosphere in A Changing Climate. New York: IPCC, pp. 158-159. Available at https://www.ipcc.ch/ site/assets/uploads/sites/3/2019/11/06_SROCC_Ch02_FINAL.pdf.

Hu RJ (2004) Physical Geography of the Tianshan Mountains in China. Beijing: China Environmental Science Press, pp. 1-14, 180-198.

Huss M (2013) Density assumptions for converting geodetic glacier volume change to mass change. The Cryosphere 7, 877-887. doi: 10.5194/ tc- $7-877-2013$
Huss M, Bauder A and Funk M (2009) Homogenization of long-term mass balance time series. Annals of Glaciology 50(50), 198-206. doi: 10.3189/ 172756409787769627

Huss $\mathbf{M}$ and Hock R (2018) Global-scale hydrological response to future glacier mass loss. Nature Climate Change 8(2), 135-140. doi: 10.1038/ s41558-017-0049-x

Immerzeel WW, Van Beek LPH and Bierkens MFP (2010) Climate change will affect the Asian water towers. Science (New York, N.Y.) 328(5984), 1382-1385. doi: 10.1126/science. 1183188

Immerzeel WW and 6 others (2014) High-resolution monitoring of Himalayan glacier dynamics using unmanned aerial vehicles. Remote Sensing of Environment 150, 93-103. doi:10.1016/j.rse.2014.04.025

Jing ZF, Jiao KQ, Yao TD, Wang NL and Li ZQ (2006) Mass balance and recession of Urumqi Glacier No. 1, Tianshan, China over the last 45 years. Annals of Glaciology 43, 214-217. doi: 10.3189/172756406781811899

Kelley JJ, Stanford K, Koci B, Wumkes M and Zagorodnov V (1994) Ice coring and drilling technologies developed by the polar ice coring office. Memoirs of National Institute of Polar Research. Special Issue 49, 24-40.

Kraaijenbrink PDA and 5 others (2016) Seasonal surface velocities of a Himalayan Glacier derived by automated correlation of unmanned aerial vehicle imagery. Annals of Glaciology 57(71), 103-113. doi: 10.3189/2016AoG71A072

Li HL (2010) Glacier dynamic models and their applicability for the Alpine Glaciers in China. Cold and Arid Regions Environmental and Engineering Research Institute Chinese Academy of Sciences.

Li ZQ, Han TD, Jing ZF, Yang HA and Qiao KQ (2003) A summary of 40-year observed variation facts of climate and Glacier No. 1 at headwater of Urumqi River, Tianshan, China. Journal of Glaciology and Geocryology 25(2), 117-123. doi: 1000-0240(2003) 02-0117-07

Li ZQ, Li HL and Chen YN (2011) Mechanisms and simulation of accelerated shrinkage of continental glaciers: a case study of Urumqi Glacier No. 1 in eastern Tianshan, central Asia. Journal of Earth Science 22(4), 423-430. doi: $10.1007 / \mathrm{s} 12583-011-0194-5$

Li ZQ and 6 others (2020) 60-year changes and mechanisms of Urumqi Glacier No. 1 in the eastern Tianshan of China, Central Asia. Sciences in Cold and Arid Regions 12(6), 380-388. doi: 10.3724/SP.J.1226. 2020.00380

Liu K, Wang NL and Bai XH (2017) Variation of glaciers in the Bubra basin, Karakorom Mountains, revealed by remote sensing images during 19932015. Journal of Glaciology and Geocryology 39(4), 710-719. doi: 10.7522/ j.issn.1000-0240.2017.0081

Liu SY and 7 others (2015) The contemporary glaciers in China base on the Second Chinese Glacier Inventory. Acta Geographica Sinica 70(1), 3-16. doi: $10.11821 / \mathrm{dl} x \mathrm{xb} 201501001$

Nuth C and Kaab A (2011) Co-registration and bias corrections of satellite elevation data sets for quantifying glacier thickness change. The Cryosphere 5(1), 271-290. doi: 10.5194/tc-5-271-2011

Østrem G and Brugman M (1991) Glacier mass-balance measurements, a manual for field and office work. Saskatoon, Sask., Environment Canada. National Hydrology Research Institute (NHRI Science Report 4).

Paterson WSB (1994) The Physics of Glacier, 3rd Edn. Oxford: Pergamon Press, pp. 238-288.

Paul F and 24 others (2015) The glaciers climate change initiative: methods for creating glacier area, elevation change and velocity products. Remote Sensing of Environment 162, 408-426. doi:10.1016/j.rse.2013.07.043

Perroy RL, Bookhagen B, Asner GPA and Chadwick AC (2010) Comparison of gully erosion estimates using airborne and ground-based LiDAR on Santa Cruz Island, California. Geomorphology 118(3-4), 288-300. doi: 10.1016/j. geomorph.2010.01.009

Rees WG and Arnold NS (2006) Scale-dependent roughness of a glacier surface: implications for radar backscatter and aerodynamic roughness modelling. Journal of Glaciology 52(177), 214-222. doi: 10.3189/172756506781828665

RIEGL Laser Measurement Systems (2014) RiSCAN PRO ${ }^{\circledR}$-Version 1.8.1, Riegl Laser Measurement Systems, Horn, Austria.

Rolstad C, Haug T and Denby B (2009) Spatially integrated geodetic glacier mass balance and its uncertainty based on geostatistical analysis: application to the western Svartisen ice cap, Norway. Journal of Glaciology 55(192), 666-680. doi: 10.3189/002214309789470950

Schneider T and Jansson P (2004) Internal accumulation in firn and its significance for the mass balance of Storglaciären, Sweden. Journal of Glaciology 50(168), 25-34. doi: 10.3189/172756504781830277

Shangguan DH and 6 others (2015) Mass changes of Southern and Northern Inylchek Glacier, Centra Tian Shan Kyrgyzstan, during 1975 and 2007 
derived from remote sensing data. The Cryosphere 9(2), 703-717. doi: 10. 5194/tc-9-703-2015

Shen YP and 7 others (2013) The response of glacier and snow cover to climate change in Xinjiang II. Cazard effects. Journal of Glaciology and Geocryology 35(6), 1355-1370. doi: 10.7522/j.issn.1000-0240.2013. 0151

Silverio W and Jaquet JM (2005) Glacial cover mapping (1987-1996) of the Cordillera Blanca (Peru) using satellite imagery. Remote Sensing of Environment 95(3), 342-350. doi: 10.1016/j.rse.2004.12.012

Simon KA, Zhang GQ, Wang WC, Yao TD and Bolch T (2019) Potentially dangerous glacial lakes across the Tibetan Plateau revealed using a large-scale automated assessment approach. Science Bulletin 64(7), 435445. doi: 10.1016/j.scib.2019.03.011

Sun MP, Liu SY, Yao XJ, Guo WQ and Xu JL (2015) Glacier changes in the Qilian Mountains in the past half century: based on the revised first and second Chinese glacier inventory. Acta Geographica Sinica 70(9), 14021414. doi: 10.1007/s11442-018-1468-y

Thibert E, Blanc R, Vincent C and Eckert N (2008) Glaciological and volumetric mass balance measurements: error analysis over 51 years, Sarennes Glacier, French Alps. Journal of Glaciology 54, 522-532. doi: 10.3189/ 002214308785837093

Wang PY (2011) Analysis on changes of ice-thickness and volume for representative glaciers in different areas of Tian Shan. Cold and Arid Regions Environmental and Engineering Research Institute Chinese Academy of Sciences, pp. 48-50.

Wang PY and 5 others (2020) Glaciers in Xinjiang, China: Past Changes and Current Status. Water 12(9), 2367. doi: 10.3390/w12092367

Wang PY, Li ZQ, Li HL, Wang WB and Yao HB (2014) Comparison of glaciological and geodetic mass balance at Urumqi Glacier No. 1, Tian Shan Central Asia. Global and Planetary Change 114, 14-22. doi: 10.1016/j.gloplacha.2014.01.001

Wang NL, Wu HB, Wu YW and Chen AA (2015) Variations of the glacier mass balance and lake water storage in the Tarim Basin, northwest China, over the period of 2003-2009 estimated by the ICESat-GLAS data. Environmental Earth Sciences 74(3), 1997-2008. doi: 10.1007/ s12665-015-4662-6

Wang PY and 7 others (2016) Analyses of recent observations of Urumqi Glacier No. 1, Chinese Tianshan Mountains. Environmental Earth Sciences 75(8), 720. doi: 10.1007/s12665-016-5551-3

Wang PY and 5 others (2017) Characteristics of a partially debris-covered glacier and its response to atmospheric warming in Mt. Tomor, Tien Shan, China. Global and Planetary Change 159, 11-24. doi: 10.1016/j.gloplacha. 2017.10.006

Wang PY and 6 others (2018) Long-term change in ice velocity of Urumqi Glacier No. 1, Tian Shan, China. Cold Regions Science and Technology 145, 177-184. doi: 10.1016/j.coldregions.2017.10.008
Wang NL, Yao TD, Xu BQ, Chen AA and Wang WC (2019) Spatiotemporal pattern, trend, and influence of glacier change in Tibetan Plateau and surroundings under global warming. Bulletin of Chinese Academy of Science 34 (11), 1220-1232. doi: 10.16418/j.issn.1000-3045.2019.11.005

Whitehead K and Hugenholtz CH (2014a) Remote sensing of the environment with small unmanned aircraft systems (UASs), part 1: a review of progress and challenges. Journal of Unmanned Vehicle Systems 2(3), 69-85. doi: 10.1139/juvs-2014-0006

Whitehead K and 8 others (2014b) Remote sensing of the environment with small unmanned aircraft systems (UASs), part 2: scientific and commercial applications. Journal of Unmanned Vehicle Systems 2(3), 86-102. doi: 10. 1139/juvs-2014-0007

Wigmore O and Mark B (2017) Monitoring tropical debris-covered glacier dynamics from high-resolution unmanned aerial vehicle photogrammetry, Cordillera Blanca, Peru. The Cryosphere 11(6), 2463-2480. doi: 10.5194/ tc-11-2463-2017

Williams RS, Hall DK, Siguresson O and Chien JYL (1997) Comparison of satellite-derived with ground-based measurements of the fluctuations of the margins of Vatnajökull, Iceland, 1973-92. Annals of Glaciology 24, 72-80. doi: $10.3189 / \mathrm{S} 0260305500011964$

Xu CH and 5 others (2017) Using an ultra-long-range terrestrial laser scanner to monitor the net mass balance of Urumqi Glacier No. 1, eastern Tien Shan, China, at the monthly scale. Journal of Glaciology 63(241), 1-11. doi: $10.1017 /$ jog. 2017.45

Xu CH and 5 others (2018) Detailed comparison of glaciological and geodetic mass balances for Urumqi Glacier No. 1, eastern Tien Shan, China, from 1981 to 2015. Cold Regions Science and Technology 155, 137-148. doi: 10. 1016/j.coldregions.2018.08.006

Xu CH, Li ZQ, Li HL, Wang FT and Zhou P (2019) Long-range terrestrial laser scanning measurements of annual and intra-annual mass balances for Urumqi Glacier No. 1, eastern Tien Shan, China. The Cryosphere 13, 2361-2383. doi: 10.5194/tc-13-2361-2019

Yang XH, Zhao JD and Han H (2019) Study on glacier mass balance in the Karlik Range, East Tianshan Mountains, 1972-2016. Journal of Glaciology and Geocryology 41(1), 1-11. doi: 10.7522 /j. issn.1000-0240. 2019. 0004

Yao TD and 14 others (2012) Different glacier status with atmospheric circulations in Tibetan Plateau and surroundings. Nature Climate Change 2(9), 663-667. doi: 10.1038/nclimate1580

Yao HB, Li ZQ, Wang PY, Huai BJ and Zhang H (2015) Area variation analysis of Urumqi Glacier No. 1 in past 50 decades. Arid Zone Research 32 (03), 442-447. doi: 10.13866/j.azr.2015.03.04

Zemp M and 16 others (2013) Reanalysing glacier mass balance measurement series. The Cryosphere 7(4), 1227-1245. doi: 10.5194/tc-7-1227-2013

Zhang QB, Kang SC and Wang J (2017) Elevation change of the Laohugou Glacier No. 12 in the western Qilian Mountains from 2000 to 2014. Journal of Glaciology and Geocryology 39(4), 733-740. doi: 10.7522/j.issn.1000-0240.2017.0083 